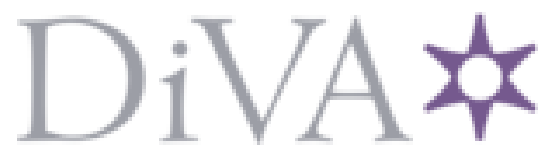

http://www.diva-portal.org

This is the published version of a paper published in IET Electric Power Applications.

Citation for the original published paper (version of record):

Sjökvist, S., Eklund, P., Eriksson, S. [Year unknown!]

Determining demagnetisation risk for two PM wind power generators with different PM material and identical stators.

IET Electric Power Applications

http://dx.doi.org/10.1049/iet-epa.2015.0518

Access to the published version may require subscription.

N.B. When citing this work, cite the original published paper.

Permanent link to this version:

http://urn.kb.se/resolve?urn=urn:nbn:se:uu:diva-291371 
This paper is a preprint of a paper accepted by IET Electric Power Applications and is subject to Institution of Engineering and Technology Copyright. When the final version is published, the copy of record will be available at IET Digital Library 


\section{Determining demagnetisation risk for two PM wind power generators with different PM material and identical stators}

ISSN 1751-8660

Received on 9th October 2015 Revised on 5th April 2016 Accepted on 7th April 2016 doi: 10.1049/iet-epa.2015.0518 www.ietdl.org

\section{Stefan Sjökvist ${ }^{凶}$, Petter Eklund, Sandra Eriksson \\ Division for Electricity, Department of Engineering Sciences, Uppsala University, Box 534, 75121 Uppsala, Sweden \\ $\bowtie$ E-mail: stefan.sjokvist@angstrom.uu.se}

Abstract: Ways to utilise ferrite permanent magnets (PMs), in a better way has been in focus the last couple of years since the use of neodymium-iron-boron (NdFeB) PMs has been debated. While ferrite PMs offer a low-cost alternative to rareearth PMs, it is a trade-off for lower energy density. Depending on the type of PM and if the PMs are surface mounted or buried, the risk of demagnetisation during a fault condition can vary significantly between machines. In this study, the emagnetisation risk of two electrically similar generators with identical stators has been studied during several shortcircuit faults at different temperatures. The study is simulation-based, and the results show that the generator with the ferrite rotor will suffer from a small but not significant amount of demagnetisation in the worst, three-phase-neutral, short-circuit case at a temperature of $5^{\circ} \mathrm{C}$, whereas the $\mathrm{NdFeB}$ PMs will suffer from partial demagnetisation if a fault occurs at $120^{\circ} \mathrm{C}$. For operational temperatures between 20 and $60^{\circ} \mathrm{C}$ both generators will sustain a short-circuit event.

\section{Introduction}

30 Neodymium-iron-boron $(\mathrm{NdFeB})$ permanent magnets, permanent magnets (PMs), offers a high energy product and are today widely used in generators and motors for different applications [1, 2]. However, the use of rare-earth metals has been debated for the last couple of years for cost and environmental reasons. As a consequence, more focus has been on investigating the use of ferrites, substituting $\mathrm{NdFeB}$, by alternating the rotor design of electrical machines [3-7]. While ferrite PMs offer a low-cost alternative to rare-earth PMs, it is a trade-off for lower energy density. A lower energy density leads to a larger magnetic volume and a higher weight of the rotor to maintain the same magnetic

40 flux density, $B$, in the machine.

When designing a PM machine the main role of the PMs is to deliver the required magnetic flux during normal operation of the machine. If the design is properly done, some non-normal operation scenarios have also been considered, e.g. when there is 4 an increase in temperature or high currents in the armature windings. An increased temperature lowers the coercivity of $\mathrm{NdFeB}$ magnets and make them more sensitive to demagnetising fields. High currents in the armature winding can cause a high magnetic field, $H$, that could damage PMs. Both these scenarios could damage a NdFeB PM. Ferrite PMs on the other hand have a

50 positive temperature coefficient for the intrinsic coercivity, $\mathrm{TC}_{H}$. In other words, the intrinsic coercivity goes up with increasing temperature and they can, as a result, withstand a higher demagnetising field when the temperature goes up. It is important to detect early if a demagnetisation has occurred. A method for this is presented in [8].

The rotor of a $12 \mathrm{~kW}$ direct driven PM generator has previously been redesigned and built with ferrites substituting $\mathrm{NdFeB}$ PMs [7]. The generator is to be used with a vertical axis wind turbine. The new generator with ferrite rotor has similar electrical properties as the old generator with $\mathrm{NdFeB}$ rotor. However, due to

60 the different characteristics of ferrites and $\mathrm{NdFeB} \mathrm{PMs} \mathrm{and} \mathrm{the} \mathrm{fact}$ that the rotor now has buried flux concentrated PMs instead of surface mounted, a new demagnetisation risk analysis is necessary. Despite the fact that the rotors are very different and therefore somewhat hard to compare, this study is motivated if one has a generator with an interchangeable rotor as in [6] as well as for evaluating ferrites as a rare-earth metal-free alternative to $\mathrm{NdFeB}$.
This article aims to evaluate the demagnetisation risk of both generators during different short-circuit events. A detailed description of the finite element method (FEM) simulation model used for the demagnetisation simulations as well as experimental verification can be found in $[9,10]$.

\section{Generator properties}

The two three-phase generators in this study have identical stators. The rotor of generator $1(\mathrm{G} 1)$, has surface mounted NdFeB PMs. The PMs in G1 are of the type 633TP from [11]. Generator 2 (G2), has buried ferrite magnets of grade Y40 (Chinese standard). The properties of the PMs are presented in Tables 1 and 2 . However, a reference value of $\mathrm{TC}_{H_{c} J}$ for the specific ferrite $\mathrm{PM}$ grade was not found. Instead, a general $\mathrm{TC}_{H_{\mathrm{c} J}}$ for ferrites was used. The two rotor configurations are shown in Fig. 1. Due to the lower energy density of ferrites and the space restriction inside the stator, the air gap has been reduced from 10 to $7 \mathrm{~mm}$ to try to maintain the same air gap magnetic flux density in G2 compared with G1. However, the magnetic flux density and consequently the voltage of G2 is slightly lower than for G1. Both the generators and the loads are Y-connected, and there is a neutral connected between the Y-connection points. The generator characteristics are presented in Table 3 [7, 12]. The rotor of G1 is non-salient whereas G2 has a small saliency. The phase inductance given in Table 3 is the $d$-axis inductance, $L_{d}$, and does not include the coil end inductance. The coil end inductance is approximately $8 \%$ of the total inductance.

\subsection{Torque}

When applying a counteracting torque to a rotating mass, the mass will start to decelerate. The rate of deceleration depends on the mass moment of inertia, $J$. The deceleration decreases with increasing moment of inertia. The moment of inertia of the NdFeB rotor, ferrite rotor, and the turbine are $16.9,34.2$ and $240 \mathrm{kgm}^{2}$, respectively $[7,13]$. Since the generators are designed to be used with a turbine, the mechanical system is expected to behave rather differently with and without the turbine. During a short-circuit, the short-circuit current should increase with increasing moment of 
Table 1 Characteristics of the magnets used in the two generators at $20^{\circ} \mathrm{C}$

\begin{tabular}{lcccc}
\hline Quantity & Abbreviation & Unit & $633 \mathrm{TP}$ & $\mathrm{Y} 40$ \\
\hline remanence & $B_{\mathrm{r}}$ & {$[\mathrm{T}]$} & 1.32 & 0.45 \\
coercivity & $H_{\mathrm{c}}$ & {$[\mathrm{kA} / \mathrm{m}]$} & -1020 & -330 \\
intrinsic coercivity & $H_{\mathrm{cJ}}$ & {$[\mathrm{kA} / \mathrm{m}]$} & -1432 & -340 \\
maximum energy product & $\mathrm{BH}_{\max }$ & {$\left[\mathrm{kJ} / \mathrm{m}^{3}\right]$} & 335 & 47.6 \\
remanence temperature & $\mathrm{TC}_{B_{\mathrm{r}}}$ & {$\left[\% /{ }^{\circ} \mathrm{C}\right]$} & -0.095 & -0.2 \\
coefficient & $\mathrm{TC}_{H_{\mathrm{c} J}}$ & {$\left[\% /{ }^{\circ} \mathrm{C}\right]$} & -0.65 & $0.3^{\mathrm{a}}$ \\
intrinsic coercivity temperature & & & & \\
coefficient & & & &
\end{tabular}

${ }^{\mathrm{a}} \mathrm{No}$ specific data was found for the temperature coefficient of the intrinsic coercivity, $\mathrm{TC}_{H_{c\lrcorner}}$, for the grade $\mathrm{Y} 40$. Instead, a general $\mathrm{TC}_{H_{c},}$ for ferrites was used

Table 2 Temperature specific data for the knee points of the magnets at the temperatures used in the study

\begin{tabular}{lccrrr}
\hline Temp. ${ }^{\circ} \mathrm{C}$ & \multicolumn{2}{c}{ 633TP, G1 } & & \multicolumn{2}{c}{ Y40, G2 } \\
\cline { 2 - 3 } \cline { 5 - 6 } & $\mathrm{B}, \mathrm{T}$ & $\mathrm{H}, \mathrm{kA} / \mathrm{m}$ & & $\mathrm{B}, \mathrm{T}$ & $\mathrm{H}, \mathrm{kA} / \mathrm{m}$ \\
\hline-25 & - & - & & 0.14 & -248 \\
5 & -0.44 & -1367 & & 0.07 & -278 \\
20 & -0.3 & -1242 & & 0.03 & -294 \\
60 & 0.08 & -911 & & -0.06 & -336 \\
120 & 0.64 & -416 & - & - \\
\hline
\end{tabular}

inertia since there is more rotating energy to be converted into electrical energy. The angular velocity of the rotor axis can be calculated by the following ordinary differential equation (ODE),

$$
\frac{\mathrm{d} \omega}{\mathrm{d} t}-\frac{\Delta \tau}{J}=0,
$$

where, $\mathrm{d} \omega / \mathrm{d} t$ is the angular acceleration, $J$ is the moment of inertia of the rotating mass and $\Delta \tau$ is the difference in torque between the turbine and the generator. In this case, the rotating mass consists of the rotor of the generator and the turbine. The axis is assumed to be stiff and have a negligible mass moment of inertia. The stiff axis assumption can be seen as a compromise between the assumptions of using constant rotational speed and fully disconnecting the rotor at the moment of the short-circuit.
Table 3 Generator properties

\begin{tabular}{lccc}
\hline Quantity & Unit & $\mathrm{G} 1$ & $\mathrm{G} 2$ \\
\hline rated power & {$[\mathrm{kW}]$} & 12 & 12 \\
phase voltage, no load (rms) & {$[\mathrm{V}]$} & 172 & 146 \\
phase voltage, load $(\mathrm{rms})$ & {$[\mathrm{V}]$} & 167 & 141 \\
armature current $(\mathrm{rms})$ & {$[\mathrm{A}]$} & 23.9 & 28.5 \\
power factor & - & 1 & 1 \\
phase resistance & {$[\Omega]$} & 0.15 & 0.15 \\
phase inductance, $L_{d}$ & {$[\mathrm{mH}]$} & 1.4 & 1.7 \\
electromagnetic efficiency & {$[\%]$} & 95.8 & 95.6 \\
rotor mass & {$[\mathrm{kg}]$} & 130 & 407 \\
stator diameter (inner/outer) & {$[\mathrm{mm}]$} & $760 / 886$ & $760 / 886$ \\
minimum air gap & {$[\mathrm{mm}]$} & 10 & 7 \\
stator length & {$[\mathrm{mm}]$} & 222 & 222 \\
rated rotational speed & {$[\mathrm{rpm}]$} & 127 & 127 \\
poles & - & 32 & 32 \\
slots per pole and phase & - & $5 / 4$ & $5 / 4$ \\
\hline
\end{tabular}

\section{Study and simulations}

This study aims to determine the short-circuit currents and the worst possible case for the PMs during several different short-circuit events given the assumptions made. The maximum current was compared for the various cases as well as the minimum $B$ inside the PMs. Only the magnetic flux density parallel to the magnetisation direction, $B_{\|}$, was taken into account when comparing the minimum $B$ inside the PMs. The same was done for the magnetic field, e.g. $H_{\|}$.

The short-circuit simulations were performed for both generators with and without a connected turbine. All short-circuit simulations were performed at $20^{\circ} \mathrm{C}$. The demagnetisation analysis was performed at $20^{\circ} \mathrm{C}$ for all generator/turbine/short-circuit combinations. The worst case for each generator, from the PMs point of view, was further analysed at $5^{\circ} \mathrm{C}$ and $60^{\circ} \mathrm{C} .5^{\circ} \mathrm{C}$ was assumed to be the lowest allowed temperature in the generator housing to avoid condensation during the winter months. $60^{\circ} \mathrm{C}$ was used as an upper limit in the study since this is close to the maximum allowed temperature of the winding insulation of $70^{\circ} \mathrm{C}$.

Further, two additional temperatures were tested on the worst performing cases to represent a more serious situation for each machine, due to the different sign of $\mathrm{TC}_{H_{c I}}$ for $\mathrm{NdFeB}$ and ferrites, see Table 1. A simulation of $\mathrm{G} 1$ was performed at $120^{\circ} \mathrm{C}$. For this case, it was assumed that the cooling system had failed and that the winding had been changed to one that can withstand
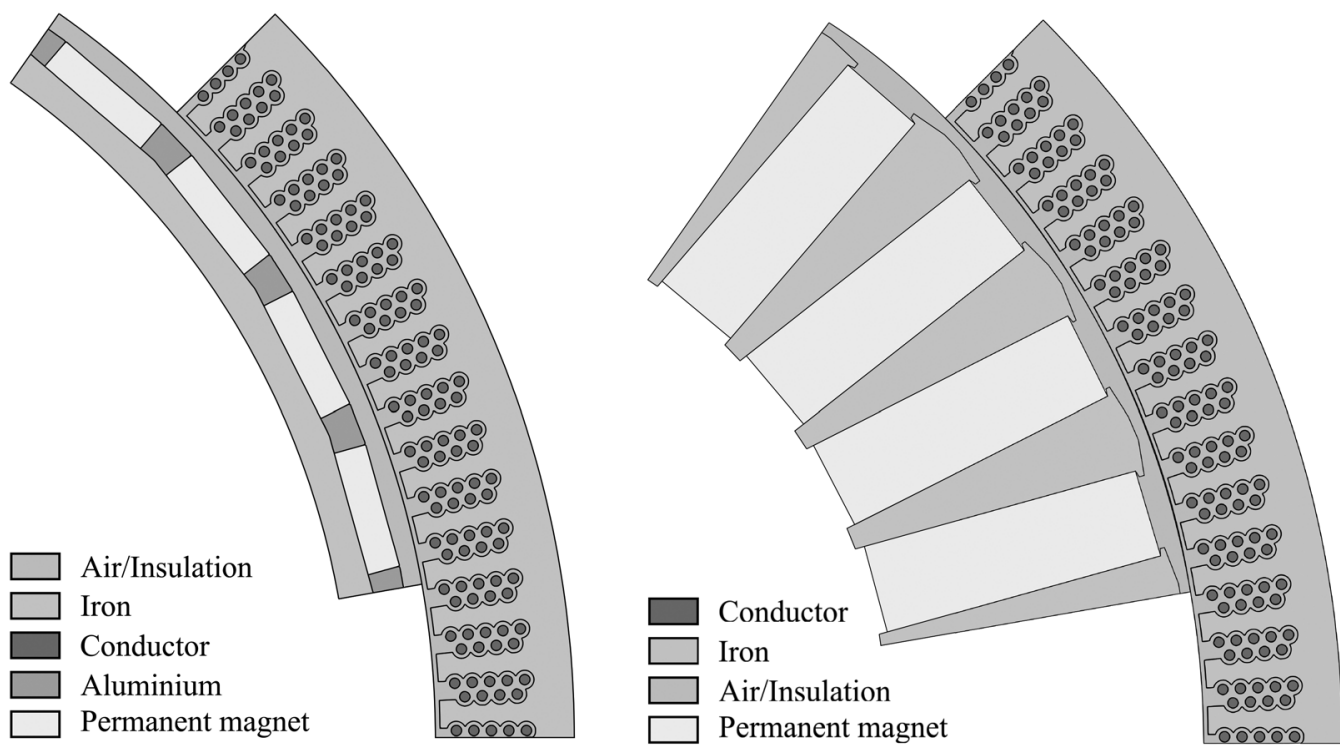

Fig. 1 Schematic figures of the two generators

$a \mathrm{G} 1$

$b \mathrm{G} 2$ 
265 higher temperature. $\mathrm{G} 2$ was tested at $-25^{\circ} \mathrm{C}$ to simulate a fault shortly after the start during winter when the heating of the generator housing had failed. All simulations were performed with 2D models and 3D effects such as leakage flux and coil end inductances were not considered. Simulations with and without a connected turbine were performed to show that the system that the generator is connected to is relevant to the results.

The study was carried out in the following sequence. First, the generator was run at no load and rated speed measuring the induced voltage in a time-dependent FEM model. Second, the short-circuit was simulated and the parameters at the worst 275 possible time, from the magnets point of view, were extracted from the time-dependent solution and inserted into a static FEM demagnetisation model, see Section 3.2. After the demagnetisation analysis, the induced voltage was measured again by running another simulation at no load and rated speed, but now with potentially damaged PMs.

The no load simulations were performed at different PM temperatures, but with a $20^{\circ} \mathrm{C}$ surrounding temperature, i.e. other temperature effects such as resistivity change in the windings were not considered.

285

\subsection{Short-circuit simulations}

The short-circuit FEM simulation is a time-dependent model based on the static Comsol Multiphysics model presented in [9].

290 Short-circuit simulations were performed to obtain the short-circuit currents for both generators. In this study, the three phases were denoted $\mathrm{A}, \mathrm{B}$ and $\mathrm{C}$. The neutral connection was denoted $N$. The tested short-circuit events were A-N, A-B, A-B-N, A-B-C and A-B-C-N. In this model, the field model was solved using a time-dependent FEM solver and the electrical circuit was solved using a coupled analytical model. In the simulations, before the short-circuit, each phase of G1 and G2 was connected to a $7.00 \Omega$ and a $4.92 \Omega$ resistive load, respectively. Different loads were used to generate the same output power for the two machines since the induced voltage somewhat differed.

300 Both generators were tested with and without a connected turbine. The short-circuit was initiated $7 \mathrm{~ms}$ into the simulation and was ramped in over a period of $2 \mathrm{~ms}$. A ramp function was used to help the solver converge and reduce numerical errors. During these simulations, a uniform temperature of $20^{\circ} \mathrm{C}$ and constant driving turbine torque on the turbine axis, was assumed to simplify the model. Assuming a stiff axis simplified the model further, adding the extra moment of inertia of the turbine to the model. The torque, $\Delta \tau$, from (1) was coupled with the simulation model and by solving the ODE the angular velocity could be obtained and coupled back into the simulation model.

\subsection{Demagnetisation simulations}

The demagnetisation simulations were performed using a static FEM 315 model developed in Comsol Multiphysics [9, 10]. The demagnetisation model is based on an exponent function model presented by Ruoho et al. [14]. The demagnetisation model only considers the magnetic field parallel to the magnetisation direction. The recoil line of the magnet is approximated by a straight line with the same slope as the linear part of the $\boldsymbol{B}-\boldsymbol{H}$ curve. Although the recoil curve will experience a slight bend upwards, a linear model has been considered sufficient for this study [15, 16]. Both $2 \mathrm{D}$ and $3 \mathrm{D}$ simulations can be performed with the model. In this study only 2D simulations were performed. The rotor position and the currents were extracted from the time-dependent simulation as 325 described above.

The ferrite PMs are partly demagnetised in the corners by just being placed in the generator. However, the affected area is small. This demagnetisation is considered in the simulation, and when presenting the demagnetisation results, i.e. the magnetisation is not

\section{Results}

In Table 4, the maximum amplitude of the currents from all short-circuit simulations for G1 and G2 are presented. The short-circuit case that resulted in the highest instantaneous peak current for all generator/turbine configurations was the A-B-N case. However, the A-B-C-N case was worst from the PMs point of view for all configurations. Further, the maximum amplitude of the current and the minimum $B_{\|}$did not necessarily coincide in time. Results of the demagnetisation analysis at $20^{\circ} \mathrm{C}$ for all configurations are presented in Table 5. The minimum $B_{\|}$inside the PMs was above the knee point of the $\boldsymbol{B}-\boldsymbol{H}$ curve in all cases for G1, i.e. the PMs did not suffer from partial demagnetisation and the induced voltage remained the same as before the short-circuits. For G2 the minimum $B_{\|}$was well below the knee point of the $\boldsymbol{B}-\boldsymbol{H}$ curve in all cases. However, the reduction of the induced rms no load phase voltage, $U_{l n}$, was $<1 \%$ for all cases. In Table 5, the grey backgrounds represent the worst performing cases; these cases were the ones further analysed at different temperatures. The voltage decreased with increasing temperature due to the lower $B$ in the PMs at elevated temperature.

None of the NdFeB PMs in G1 suffered from partial demagnetisation at any of the standard temperatures, only in the extreme case of $120^{\circ} \mathrm{C}$. In this case, the partial demagnetisation resulted in a decrease in $U_{l n}$ by $28 \%$ with the turbine connected and $7 \%$ without the turbine. All demagnetisation results for G1 with the turbine for the A-B-C-N case is presented in Table 6 .

Table 4 Maximum amplitude of the currents during all tested short-circuit events

\begin{tabular}{|c|c|c|c|c|}
\hline \multirow[b]{2}{*}{ S.C. type } & \multicolumn{2}{|c|}{ G1 } & \multicolumn{2}{|c|}{ G2 } \\
\hline & $\begin{array}{c}\text { Turbine } \\
\text { Max } \mid I_{s c} l, A\end{array}$ & $\begin{array}{l}\text { No turbine } \\
\text { Max } \mid I_{s c} l, A\end{array}$ & $\begin{array}{c}\text { Turbine } \\
\operatorname{Max}\left|I_{s c}\right|, A\end{array}$ & $\begin{array}{l}\text { No turbine } \\
\text { Max }\left|I_{s c}\right|, A\end{array}$ \\
\hline$A-N$ & 759 & -415 & 482 & 419 \\
\hline$A-B$ & 579 & 290 & 367 & 320 \\
\hline A-B-N & 827 & -522 & -526 & -461 \\
\hline$A-B-C$ & 648 & -441 & 377 & 350 \\
\hline A-B-C-N & -743 & 376 & 496 & 439 \\
\hline
\end{tabular}

$A, B$ and $C$ represent the three phases of the generators and $N$ represents the neutral. The short-circuit case with the highest current amplitude is marked with a grey background for each generator/turbine configuration.

Table 5 Minimum $B_{\|}$at any given time inside the PMs of G1 and G2 during the tested short-circuit events

\begin{tabular}{|c|c|c|c|c|}
\hline \multirow[b]{2}{*}{ S.C. type } & \multicolumn{2}{|c|}{ G1 } & \multicolumn{2}{|c|}{ G2 } \\
\hline & $\begin{array}{l}\text { Turbine } \\
\min . B_{\|}, T\end{array}$ & $\begin{array}{l}\text { No turbine } \\
\text { min. } B_{\|}, T\end{array}$ & $\begin{array}{l}\text { Turbine } \\
\min . B_{\|,}, T\end{array}$ & $\begin{array}{l}\text { No turbine } \\
\min . B_{\|}, T\end{array}$ \\
\hline A-N & 0.414 & 0.553 & -0.797 & -0.792 \\
\hline$A-B$ & 0.367 & 0.620 & -0.896 & -0.852 \\
\hline$A-B-N$ & 0.391 & 0.515 & -0.914 & -0.917 \\
\hline$A-B-C$ & 0.380 & 0.483 & -0.766 & -0.787 \\
\hline A-B-C-N & 0.338 & 0.472 & -0.932 & -0.925 \\
\hline
\end{tabular}

Short-circuit case with the lowest $B_{\|}$is marked with a grey background for each generator/turbine configuration

Table 6 Results for $\mathrm{G} 1$ with turbine at different temperatures at the A-B-C-N short circuit

\begin{tabular}{lrccc}
\hline Temp. ${ }^{\circ} \mathrm{C}$ & Min $B_{\|,}, \mathrm{T}$ & $\operatorname{Min} H_{\|}, \mathrm{kA} / \mathrm{m}$ & $U_{\text {In }}$ before s.c., $\mathrm{V}$ & $U_{I n}$ after s.c., $\mathrm{V}$ \\
\hline 5 & 0.348 & -765 & 177.4 & 177.4 \\
20 & 0.338 & -704 & 172.3 & 172.3 \\
60 & 0.312 & -740 & 167.6 & 167.6 \\
120 & -0.082 & -443 & 159.6 & 114.9 \\
\hline
\end{tabular}


Table 7 Results for G2 with turbine at different temperatures at the A-B-C-N short circuit

400

\begin{tabular}{lcccc}
\hline Temp. ${ }^{\circ} \mathrm{C}$ & Min $B_{\|,} \mathrm{T}$ & Min $H_{\|,}, \mathrm{kA} / \mathrm{m}$ & $U_{l n}$ before s.c., $\mathrm{V}$ & $U_{\text {In }}$ after s.c., $\mathrm{V}$ \\
\hline-25 & -0.970 & -408 & 155.3 & 149.0 \\
5 & -0.951 & -423 & 149.5 & 148.7 \\
20 & -0.932 & -425 & 146.2 & 146.0 \\
60 & -0.723 & -402 & 136.7 & 136.7 \\
\hline
\end{tabular}

405
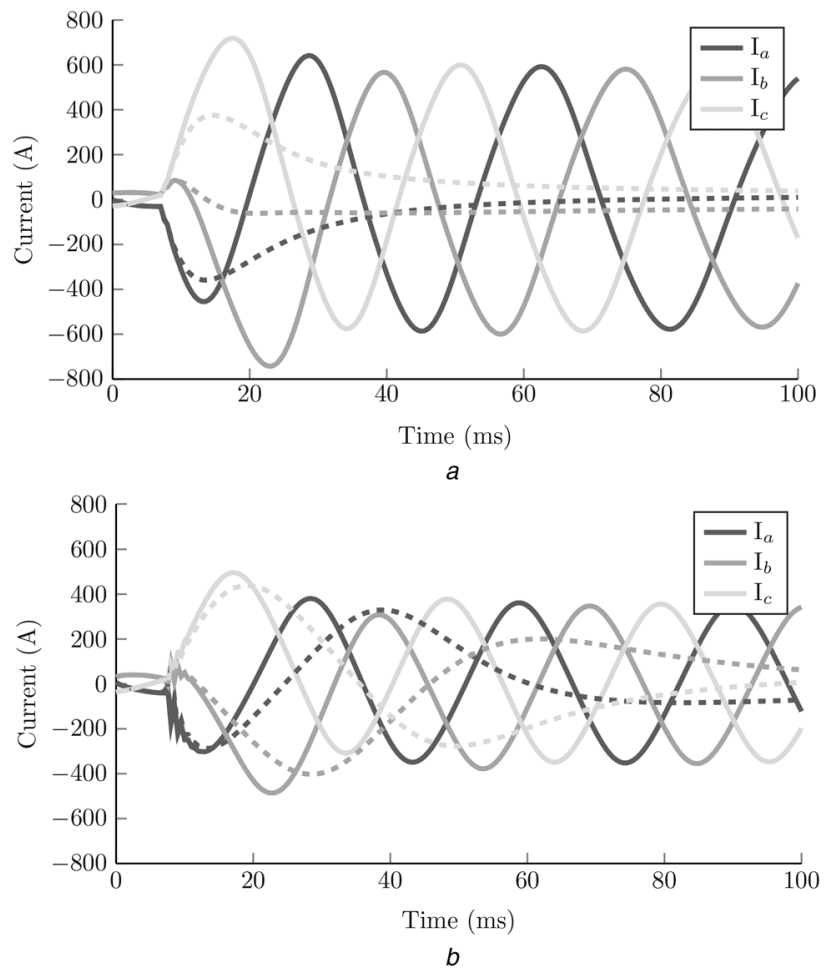

Fig. 2 Phase currents during an A-B-C-N short-circuit for $G 1$ and $G 2$. The solid and dashed lines are with and without turbine, respectively. The short-circuit occurred at $7 \mathrm{~ms}$

$a \mathrm{G} 1$

$b \mathrm{G} 2$

Fig. 3 Distribution of demagnetisation for the magnets in $G 2$ at $5^{\circ} \mathrm{C}$. The black areas represent damaged areas with a maximum demagnetisation of $27 \%$. In the majority of the demagnetised areas, the magnetisation has been reduced by $<1 \%$ from its original value
The ferrite PMs in G2 suffered from partial demagnetisation at all the tested temperatures. The maximum reduction of $U_{l n}$ occurred at $5^{\circ} \mathrm{C}$ with a connected turbine and was $0.6 \%$. At the extreme temperature of $-25^{\circ} \mathrm{C}$, the $U_{l n}$ was reduced by $4 \%$ with a turbine and $3 \%$ without a turbine. In Table 7 , results for $\mathrm{G} 2$ with turbine for the A-B-C-N case is presented.

Fig. 2 presents the currents in both machines during an A-B-C-N short-circuit. In Fig. 3, the amount of demagnetisation is shown for G2 after an A-B-C-N short-circuit at $5^{\circ} \mathrm{C}$. The major parts of the demagnetised areas are damaged less than $1 \%$, but the maximum demagnetisation was $27 \%$ according to the simulation.

\section{Discussion}

By comparing the currents for each generator in Fig. 2 and in Table 4 it can consistently be seen that the current is lower when the turbine is disconnected from the rotor. This decrease in current is because of the system's lower mass moment of inertia, i.e. when the moment of inertia is decreased, there is less energy stored in the rotating mass that can be converted into electrical energy. Further, in Fig. $2 b$ the small current ripple close after the short-circuit is caused by numerical errors which does not significantly influence the rest of the simulation results.

As mentioned in Sections 2 and 3, the coil end inductance is not considered in these simulations. Doing so, would have slightly reduced the short-circuit currents since the inductance becomes slightly higher.

As presented in Section 4 the A-B-N short-circuit caused the highest currents for all configurations. However, the worst short-circuit case from the PMs point of view was the A-B-C-N case, when there are high currents in all the three phases.

The results show that the ferrite PMs suffered from partial demagnetisation at all temperatures, but the induced voltage was not significantly changed. This is due to high but very local demagnetisation. In other words, the air gap flux density is not affected much by the short-circuit.

The initial demagnetisation of the ferrite PMs mentioned in Section 3.2 was probably less than what would have been the case for real PMs, since the low energy product of ferrites makes them sensitive to high reluctance magnetic circuits, e.g. being placed in air. This, together with their sensitivity to cold temperatures, which could have been the case if they had been shipped by aeroplane, makes it not unlikely that they could have been more damaged before being placed in the generator.

When analysing the results in Tables 6 and 7 with the PMs knee points in Table 2, different trends can be found. Comparing the difference between the minimum $H_{\|}$with $H$ in Table $2, \Delta H$, for increasing temperature, a decreasing trend can be found for the 633TP PMs in G1, but an increasing trend for the Y40 PMs in G2.

The induced voltages after the short-circuits which are presented in Tables 6 and 7 are from simulations running at the same temperature as stated in the tables. If the temperature is returned to, e.g. $20^{\circ} \mathrm{C}$, it is expected that the $U_{l n}$ will recover the same amount with which it was changed due to the temperature difference from $20^{\circ} \mathrm{C}$.

When an opposing magnetic field reaches the pole shoe in a rotor, it will prefer the path with the lowest reluctance to complete its circuit. The reluctance over the ferrite PMs is higher than between the pole shoes in the air gap. The magnetic field will, therefore, prefer to go directly to the next pole shoe in the air gap rather than through the PM. If the opposing field is high, the corners of the pole shoe will saturate, and the reluctance will go up. In this case, more of the opposing field will pass through the magnet. The pole shoes can be seen as a built in demagnetisation protection for the PMs. This protection can be adjusted by changing the width and thickness of the pole shoes. However, making them wider will allow for more leakage flux to go between the pole shoes. For surface mounted PMs an opposing field does not have any other choice than going through the PMs. 


\section{Conclusions}

530

Both generators in the study performed well in the tested short-circuit cases and operational temperatures. It was only at the extreme temperatures where the PMs were significantly demagnetised. It was found that the worst situation in time for the PMs did not necessarily coincide with the time of the maximum current. The results also show the importance of considering the mass moment of inertia in short-circuit simulations. The ferrite $\mathrm{PMs}$ in this study does, despite inferior magnetic properties compared with $\mathrm{NdFeB}$, show similar results as $\mathrm{NdFeB}$. Thanks to the protecting pole shoes the ferrites performed equally well as

$540 \mathrm{NdFeB}$. The equal performance of both generator types motivates substitution of rare-earth PMs with ferrites.

\section{Acknowledgments}

This work was carried out with funding from the Swedish Research Council, grant no. 2010-3950 and within the StandUP for Energy strategic research framework.

\section{References}

1 Morimoto, S.: 'Trend of permanent magnet synchronous machines', IEEJ Trans. Electr. Electron. Eng., 2007, 2, (2), pp. 101-108

2 Chen, Y., Pillay, P., Khan, A.: 'PM wind generator topologies', IEEE Trans. Ind. Appl., 2005, 41, (6), pp. 1619-1626

3 Demmelmayr, F., Weiss, B., Troyer, M., et al.: 'Comparison of PM-machines with ferrite and NdFeB magnets in terms of machine performance and sensorless start-up control'. 2013 IEEE Int. Conf. on Industrial Technology (ICIT), February 2013, pp. 272-277

4 Barcaro, M., Bianchi, N.: 'Interior PM machines using Ferrite to substitute rare-earth surface PM machines'. 2012 XXth Int. Conf. on Electrical Machines (ICEM), September 2012, pp. 1339-1345

5 Sekerak, P., Hrabovcova, V., Onufer, M., et al.: 'Synchronous motors with different pm materials'. ELEKTRO, 2012, May 2012, pp. 241-246

6 Eriksson, S., Bernhoff, H.: 'Rotor design for PM generators reflecting the unstable neodymium price'. 2012 XXth Int. Conf. on Electrical Machines (ICEM) September 2012, pp. 1419-1423

7 Eklund, P., Sjökvist, S., Eriksson, S., et al.: 'A complete design of a rare-earth metal-free permanent magnet generator', Machines, 2014, 2, (2), pp. 120-133

8 Urresty, J., Riba, J., Romeral, L.: 'A back-emf based method to detect magnet failures in PMSMs', IEEE Trans. Magn., 2013, 49, (1), pp. 591-598

9 Sjökvist, S., Eriksson, S.: 'Study of demagnetization risk for a $12 \mathrm{~kW}$ direct driven permanent magnet synchronous generator for wind power', Energy Sci. Eng., 2013, 1, (3), pp. 128-134

10 Sjökvist, S., Eriksson, S.: 'Experimental verification of a simulation model for partial demagnetization of permanent magnets', IEEE Trans. Magn., 2014, 50, (12), pp. 1-5

11 Vacuumschmelze GmbH. Available at http://www.vacumschmelze.com/, retrived November 19th, 2014

12 Eriksson, S., Solum, A., Leijon, M., et al.: 'Simulations and experiments on a 12 kW direct driven PM synchronous generator for wind power', Renew. Energy, 2008, 33, (4), pp. 674-681

13 Bülow, F., Eriksson, S., Bernhoff, H.: 'No-load core loss prediction of PM generator at low electrical frequency', Renew. Energy, 2012, 43, pp. 389-392

14 Ruoho, S., Dlala, E., Arkkio, A.: 'Comparison of demagnetization models for finite-element analysis of permanent-magnet synchronous machines', IEEE Trans. Magn., 2007, 43, (11), pp. 3964-3968

15 Ruoho, S., Arkkio, A.: 'Partial demagnetization of permanent magnets in electrica machines caused by an inclined field', IEEE Trans. Magn., 2008, 44, (7) pp. $1773-1778$

16 Lovatt, H.C., Watterson, P.A.: 'Energy stored in permanent magnets', IEEE Trans. Magn., 1999, 35, (1), pp. 505-507 